3. Polosa R, Caponnetto P, Morjaria J, et al. Effect of an electronic nicotine delivery device (e-Cigarette) on smoking reduction and cessation: a prospective 6-month pilot study. BMC Public Health 2011; 11:786.

CMAJ 2014. DOI:10.1503/cmaj.114-0007

\section{Expanding scope of pharmacists}

We thank Tannenbaum and Tsuyuki ${ }^{1}$ for their review in CMAJ. In addition to what the authors have already highlighted, it is also well known that clinical pharmacy services improve patient outcomes and reduce mortality in the inpatient setting and that professional collaboration is key to successful clinical pharmacy service provision. ${ }^{2,3}$

An example of this collaborative practice model is the Antimicrobial Stewardship Program (ASP) at the Children's Hospital of Winnipeg, in Manitoba. Antibiotics are commonly prescribed to children admitted to hospital, are often associated with prescribing errors, and their misuse drives antimicrobial resistance. ${ }^{4}$ ASPs help minimize inappropriate antimicrobial use, and guidelines on their development have been published. ${ }^{5}$ Accreditation Canada includes ASPs as a Required Organization Practice (ROP) in their accreditation standards. ASPs are "support" teams; core members include a physician and a clinical pharmacist with training in infectious diseases. ${ }^{6}$ Antimicrobial use is reviewed by the ASP team at both patient and system levels in order to promote safe and quality care. Teams interact with the prescribing clinician at the time of antibiotic prescribing; this face-to-face feedback from an ASP pharmacist allows for reciprocal communication in a timely, collaborative fashion, which affects the quality of care provided.

Real-world application of pharmacist-led ASPs has been shown to have the ability to lower overall inpatient antimicrobial use. ${ }^{7}$ At our institution, prescribers are open to feedback from colleagues of different professional backgrounds. We hope that this example of physician-pharmacist collaboration encourages others to explore options to synergistically improve patient care regardless of their practice setting.

\section{Sergio T. Fanella MD, Ashley Walus} BScPharm

Pediatric ASP Director (Fanella); Pediatric ASP Pharmacist (Walus), Children's Hospital of Winnipeg, Winnipeg, Man.

\section{References}

1. Tannenbaum C, Tsuyuki RT. The expanding scope of pharmacists' practice: implications for physicians. CMAJ 2013;185:1228-32.

2. Bond CA, Raehl CL. Clinical pharmacy services, pharmacy staffing, and hospital mortality rates. Pharmacotherapy 2007;27:481-93.

3. Kaboli PJ, Hoth AB, McClimon BJ, et al. Clinical pharmacists and inpatient medical care: a systematic review. Arch Intern Med 2006;166:955-64.

4. Levy ER, Swami S, Dubois SG, et al. Rates and appropriateness of antimicrobial prescribing at an academic children's hospital, 2007-2010. Infect Control Hosp Epidemiol 2012;33:346-53.

5. Dellit TH, Owens RC, McGowan JE, et al. Infectious Disease Society of America and the Society for Healthcare Epidemiology of America guidelines for developing an institutional program to enhance antimicrobial stewardship. Clin Infect Dis 2007; 44:159-77.

6. 2013 required organizational practices handbook Ottawa (ON): Accreditation Canada; 2013.Available: www.accreditation.ca/news-and-publications /publications/ROP-handbook-2013/ (accessed 2013 Oct. 20)

7. Newland JG, Stach LM, De Lurgio SA, et al. Impact of a prospective-audit-with-feedback antimicrobial stewardship program at a children's hospital. J Pediatr Infect Dis Soc 2012;1:179-86.

\section{CMAJ 2014. DOI:10.1503/cmaj.114-0008}

\section{Patient advocacy}

I read the CMAJ Salon article by Arya ${ }^{1}$ with interest and some degree of selfassessment. The author not only provides a fascinating array of physicianbased advocacy, but also touches upon the delicate balance between advocacy and empowerment.

Looking at my own practice and those of some of my colleagues, I can appreciate three reasonably distinct styles of physician-based advocacy: advocacy for health-related issues, for non-health-related issues and nonspecific advocacy.

Arya $^{1}$ cites obvious samples of advocacy to "promote the health of individuals, communities or populations." This includes direct and indirect health initiatives. Clearly, this unique contribution of physicians is the natural extension of training and expertise as medical practitioners. Not surprisingly, such advocacy remains generally uncontested and powerful.

Physician advocacy for non-healthrelated issues may be just as powerful, but may not be a natural extension of training and expertise. Furthermore, it may be far more contentious, depending upon the geopolitical milieu in which the advocacy occurs. In the context of divergent opinions regarding such advocacy, one could reasonably question the appropriateness of physician advocacy for non-health-related issues. However, nonspecific advocacy appears to be on the rise and is more troubling. I sometimes see physicians uncritically reiterating what their patients say, often without corroborating evidence, and at times, inconsistent with the expected course of events. A common example is the physician who advocates on behalf of a patient who is pursuing long-term disability benefits in the context of remote soft tissue injuries that have long-since healed. Although the physician has the best intentions, such advocacy may not be what is physically or psychologically best for the patient. This difficult issue was addressed some time ago by the American Medical Association.

As difficult as it may be, we must, with understanding and compassion, objectively assess impairment and not confuse our role as the patient's advocate with our responsibility for objectivity. ${ }^{2}$

More and more, I see physicians equating advocacy for health-related issues with nonspecific advocacy. However, we must ensure that when we advocate on behalf of our patients, our actions are consistent with available clinical evidence and are truly based upon the principle of "promoting health interests," rather than simply fulfilling expectations.

\section{John C. Clifford MD}

Department of Physical Medicine and Rehabilitation, Western University, London, Ont.

\section{References}

1. Arya N. Advocacy as medical responsibility. CMAJ 2013;185:1368.

2. Aronoff GM. Pain. In: Demeter SL, Andersson GBJ, Smith GM, editors. Disability evaluation. St. Louis (MO): American Medical Association/Mosby; 1996.

CMAJ 2014. DOI:10.1503/cmaj.114-0009

Some letters have been abbreviated for print. See www.cmaj.ca for full versions and competing interests. 